\title{
Fluid-thermal analysis of the cooling capacity of a commercial natural ester in a power transformer
}

\author{
Fernando Delgado ${ }^{1}$, Inmaculada Fernandez ${ }^{1}$, Domingo Urquiza ${ }^{2}$, Bekir Mumyakmaz ${ }^{3}$, Abdurrahman Unsal ${ }^{3}$ \\ ${ }^{1}$ Department of Electrical and Energy Engineering \\ E.T.S.I. Industriales y de Telecomunicación, Cantabria University \\ Av. De Los Castros, s/n, 39005, Santander (Spain) \\ Phone/Fax number:+34 9422013 76/85; e-mail: delgadof@unican.es \\ ${ }^{2}$ CEIS. Centro de Ensayos, Innovación y Servicios \\ Cr. Villaviciosa de Odón a Móstoles (M-856) Km. 1,5 \\ Móstoles 28935 (Spain) \\ ${ }^{3}$ Department of Electrical and Electronics Engineering \\ Dumlupinar University \\ 43100, Kutahya (Turkey)
}

\begin{abstract}
The low fire safety and high environmental impact of the mineral oil of the power transformers are two factors that have a negative influence in the goals of maximizing the return on investment and lowering the total costs associated with power system operation. Thus, many studies about alternative liquids (natural and synthetic esters, silicon oil) are being developed worldwide. This paper studies the cooling characteristics of a commercial natural ester in comparison with a traditional insulating mineral oil. A fluid-thermal simulation is done in a 3D-model of a partial cross-section of a single phase of a three-phase power transformer. The comparison of temperatures, velocities and dimensionless numbers ( $\mathrm{Re}$ and $\mathrm{Pr}$ ) of both fluids allows concluding that the direct substitution of the traditional liquid by the new one is not possible since the cooling characteristics of the latter one is quite worse than the first one.
\end{abstract}

\section{Key words}

Power transformers, alternative dielectric fluids, natural ester, 3D simulation.

\section{Introduction}

The power transformer is a very important part of the investment in transmission and distribution substations worldwide. It is also well known that power transformer failures have a considerable economic impact on the operation of an electrical network. Therefore, it is necessary that they work in good conditions in order to meet the goals of maximizing the return on investment and lowering the total costs associated with power system operation.

Among others, fire safety and environmental impact are two factors that have great influence in the aforementioned goals since the mineral oil (dielectric liquid used in almost all the power transformers worldwide) has low ignition point and it is "nonenvironmental friendly" [1]. These reasons, and others, have led to consider alternative oils, such as the natural esters and silicone oils: FR-3, Biotemp, MIDEL 7131, MIDEL eN, Dow Corning ${ }^{\circledR}$ 561, Bluesil 604V59, KF-96, etc. Nonetheless, in advance to their implantation, it is necessary a huge research activity in order to give reliable and prompt answers in relation to their effects in the design and lifetime of the transformers.

Fluid-thermal behaviour of these new fluids is an essential aspect to study since the cooling of the transformer is one of its two functions (the other one is the electric insulation). Moreover, designers are obliged to keep temperatures on power transformers under certain limits; otherwise the isolation materials can suffer very much this situation while its life expectancy is reduced considerably. In fact, there is a guide that fixes $65{ }^{\circ} \mathrm{C}$ of average winding temperature rise at rated load for mineral-oilimmersed transformers [2]. Thus, the load that a transformer can deal with it is highly dependent on the cooling conditions under which the transformer is working. For the previous reasons, dielectric fluids must provide appropriate cooling in order to avoid overheating and aging temperatures in solid and liquid insulations. It is known that the location of areas with higher temperatures -so-called hot-spots- is a key factor in the proper refrigeration design.

This article carries out a theoretical fluid-thermal study of a dielectric commercial fluid based on a natural ester. The velocities, temperatures and dimensionless numbers that characterize the behaviour of this fluid are compared with the same variables of a commercial mineral oil (Nynas Nytro 10 Gbn) in a 3D geometric model of a partial crosssection of a single phase of a three-phase power transformer. This task has been performed by means of the tool Comsol Multiphysics 4.2, based on finite element method. 


\section{Model definition}

This section presents the geometry studied, the physics, the assumptions and parameters that are considered in the model.

\section{A. Transformer geometry studied}

Using as a base the paper [3] and the congress's paper [4], the geometry studied here belongs to an oil-cooled ringshaped three-phase power transformer. In fact, it is used a $3 \mathrm{D}$ model of this transformer with the intention to obtain a better accuracy than the models used in these papers. This 3D model portrays $90^{\circ}$ of a partial cross-section of a single phase (see Figure 1).

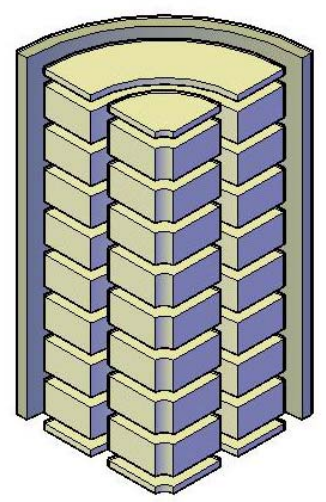

Figure 1. 3D design of the geometry studied

The 3D geometry has 10 rows of blocks which are located in the center of the coil, since the characteristic flow occurs in this part of this coil. The block section of the conductor coils is $15 \times 25 \mathrm{~mm}$. The radial separation between coils columns is $10 \mathrm{~mm}$ and the vertical separation between blocks is $5 \mathrm{~mm}$. Also, the separation of the inner column to the center is $5 \mathrm{~mm}$. Finally, the gap between the second column and the outer wall is $10 \mathrm{~mm}$.

\section{B. Physics and assumptions considered}

First, the heat transfer and the fluid mechanic are the two physical sciences that are interacting inside the transformer when the cooling is occurring. As a first assumption, it is considered that this interaction occurs in stationary regime.

In relation to the heat transfer, it is supposed a general energy balance by means the eq. (1).

$$
\nabla(-k * \Delta T)=Q-\rho C_{p} u * \Delta T
$$

Where:

$k$ - Temperature-dependent thermal conductivity

$C_{p}$ - Temperature-dependent specific heat capacity

$\rho$ - Temperature-dependent density
$Q$ - Heating power per unit volume (for this model, $\mathrm{Q}=32,400 \mathrm{~W} / \mathrm{m}^{3}$ )

$$
\boldsymbol{u} \text { - Fluid velocity }
$$

Regarding the second physics, this has been considered by means of the Weakly Compressible Navier-Stokes equations and mass conservation equation (See eq. (2) and (3)).

$$
\rho u * \nabla u=\nabla\left[\begin{array}{c}
-p I+\eta *\left(\nabla u+(\nabla u)^{T}\right) \\
-\left(\frac{2 \eta}{3}\right)(\nabla u) I \\
\nabla(\rho u)=0
\end{array}\right]+\rho g
$$

Where:

$p$ - Pressure field

$\eta$ - Temperature-dependent viscosity

The boundary conditions are the following ones:

- For the physics of fluid mechanics:

- It is fixed a uniform inlet velocity of $5 \mathrm{~mm} / \mathrm{s}$ in $\mathrm{z}$ direction at the bottom of the section.

- It is fixed a constant pressure $(0 \mathrm{~Pa})$ at the top boundary.

- $r$-velocity is zero.

- In all coil surfaces and in the outer wall is considered the no-slip condition.

- For the physics of heat transfer:

- The oil inlet temperature is $50^{\circ} \mathrm{C}$.

- The heat flux is made by convection at the outlet.

- The outer wall is insulated.

- The outer boundaries of the top and the bottom conductors are insulated.

- For both physical sciences:

- Axisimmetry condition at $\mathrm{r}=0$.

\section{Model parameters}

The heat transfer coefficient of the oils depends, among other properties, on density $\left(\rho_{\text {oil }}\right)$, thermal conductivity $\left(\mathrm{k}_{\mathrm{oil}}\right)$, heat capacity $\left(\mathrm{C}_{\mathrm{pOil}}\right)$ and dynamic viscosity $\left(\eta_{\mathrm{oil}}\right)$. In fact, it is necessary to get these physicochemical properties, which depend on the temperature, in order to enter them as input data in the model. In the case of the mineral oil, these properties have been obtained from [5]. In contrast, in the case of the vegetable oil (a natural ester), the same properties have been calculated from its technical data. These data (properties versus temperature) has been entered in a spreadsheet. Then, the mathematical expressions of the trend lines of the four properties have been calculated. Table 1 shows these mathematical

\begin{tabular}{|c|c|c|}
\hline & Mineral oil & Vegetable oil \\
\hline Density $\left[K g / m^{3}\right]$ & $\rho=875.6-0.63 T$ & $\rho=935.93-0.6376 T$ \\
\hline Thermal conductivity $\left[W /\left(m *{ }^{\circ} K\right)\right]$ & 0.125 & $k=0.1651+0.00009 T$ \\
\hline Specific heat capacity $\left[/\left(K g *{ }^{\circ} \mathrm{K}\right)\right]$ & $C_{p}=1960+4.005 T$ & $C_{p}=1715+6.75 T$ \\
\hline Dynamic viscosity $[K g /(m * s)]$ & $\eta=\rho * 10^{(-4.726-0.0091 * T)}$ & $\eta=0.134 \cdot e^{-0.03 T}$ \\
\hline
\end{tabular}
expressions for both dielectric fluids, expressed in degrees Celsius.

Table 1. Temperature-dependent properties of both dielectric liquids 


\section{Results}

This section presents the results of temperature, velocity and dimensionless numbers, which are obtained from the simulation, in order to analyze the cooling capacity of both fluids by means of the fluid-thermal interaction between the oil and the windings.

\section{Temperature results}

Figure 2 shows the temperatures of both fluids inside the transformer by means of a colors scale. First, it is necessary to mention that the maximum temperature is obtained at the top of the transformer that is refrigerated by the natural ester fluid $\left(51.49^{\circ} \mathrm{C}\right)$.
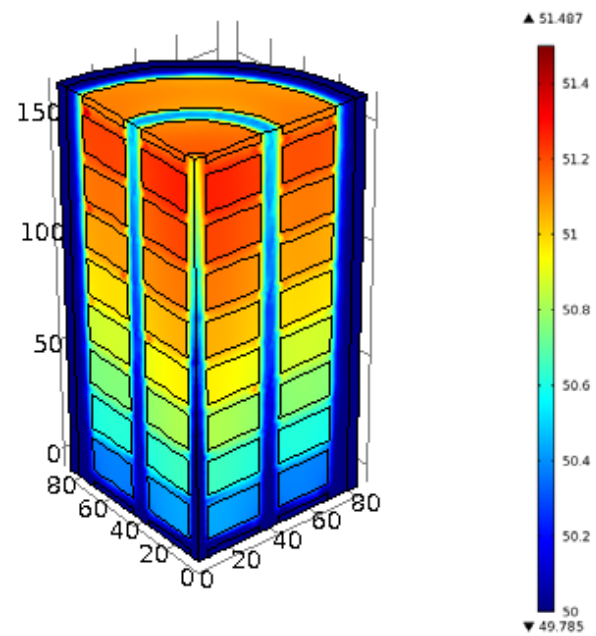

Figure 2a. Vegetable oil

Figure 2. Temperature distribution of both fluids
On the other hand, in the case of mineral oil, there is a non-isothermal distribution in r-direction. In fact, the inner coil is hotter than the outer one. In contrast, in the case of the vegetable oil, this distribution is practically isothermal.

These asseverations can be confirmed by means of the temperatures in the horizontal channels (See Figure 3). The temperatures of the natural ester in the horizontal channels that are at the same height, shown in Figure 3a, are practically the same. In contrast, there is a significant asymmetry between temperatures of the horizontal outer channels and the inner ones (See Figure 3b). That is, the refrigeration of both coils with natural ester is similar; in contrast, the outer winding is cooled better than the inner one with mineral oil.

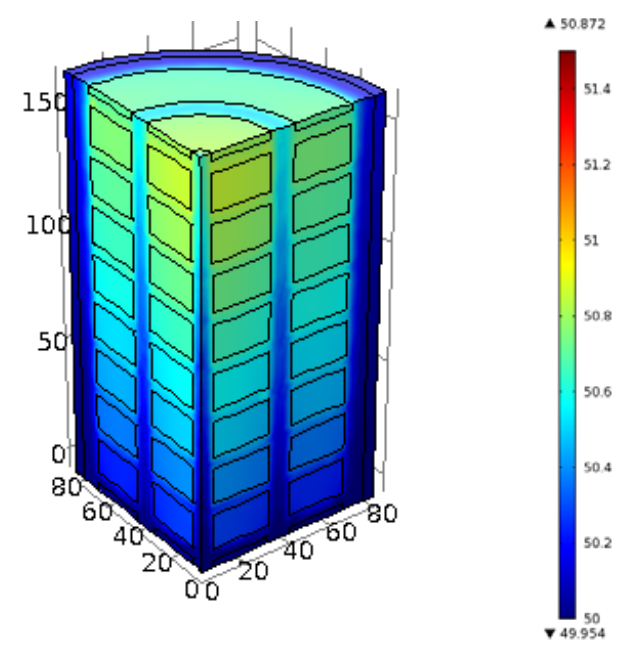

Figure 2b. Mineral oil

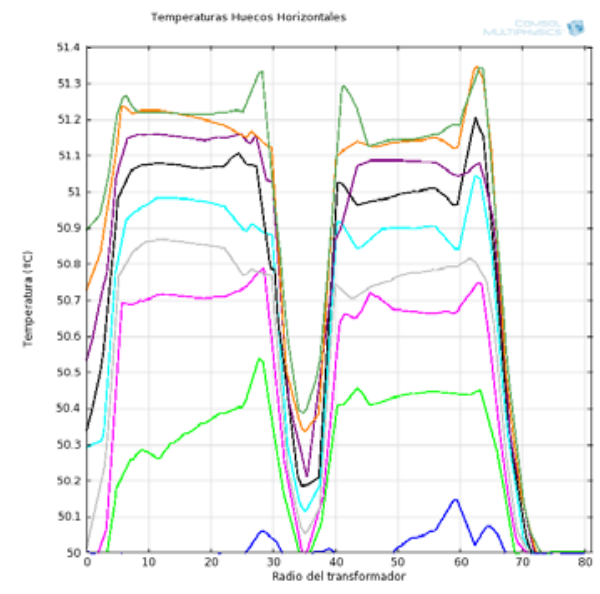

Figure 3a. Vegetable oil

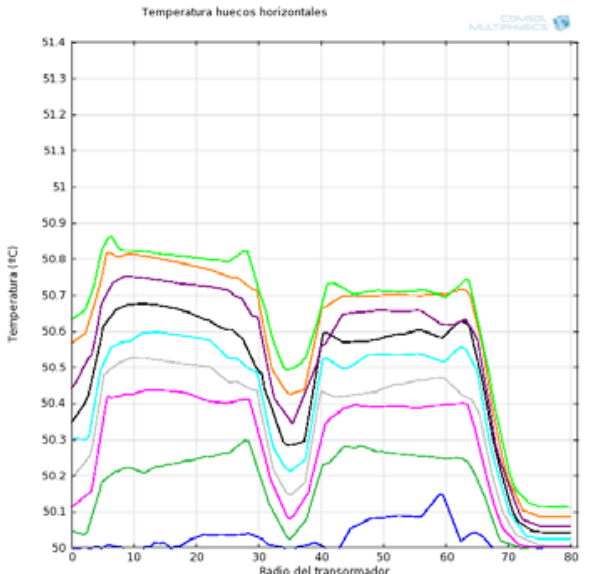

Figure 3b. Mineral oil

Figure 3. Temperatures in r-direction in horizontal channels.

\section{Velocity results}

This section presents the velocity results in all the geometry of the model. The magnitude and the flow type in the channels are related with the temperatures in the windings. That is, the refrigeration depends on these two factors.

Figure 4 presents the vertical velocity $(\mathrm{mm} / \mathrm{s})$ of both fluids by means of a colors scale. The velocities distribution in both cases is similar: the $\mathrm{v}_{\max }$ is reached at the top of the verticals ducts (natural ester: $75.29 \mathrm{~mm} / \mathrm{s}$ (Figure 31a); mineral oil: 71.37 mm/s (Figure 31b)).

In both cases, the radial velocities, shown in Figure 5, are very small or negligible. This means that the oil flows in the horizontal channels are very small, and so, the refrigeration is scarce in these ducts. However, it is shown in the aforementioned figure that there is fluid movement in the vertical channels. Thus, the velocities of 
both liquids are increased rapidly in the two outer vertical channels up to values that are close to $60-70 \mathrm{~mm} / \mathrm{s}$ (See Figure 6).
Nonetheless, the vertical velocities in the inner channel have the opposite tendency: they fall quickly from values close to $60 \mathrm{~mm} / \mathrm{s}$ to values between $5-10 \mathrm{~mm} / \mathrm{s}$.

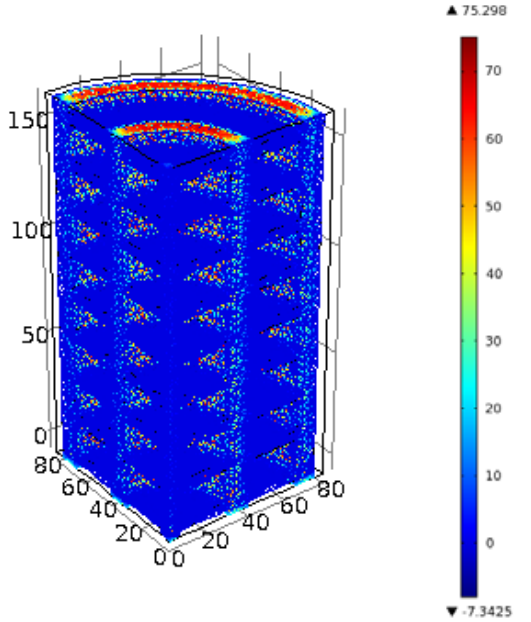

Figure 4a. Vegetable oil

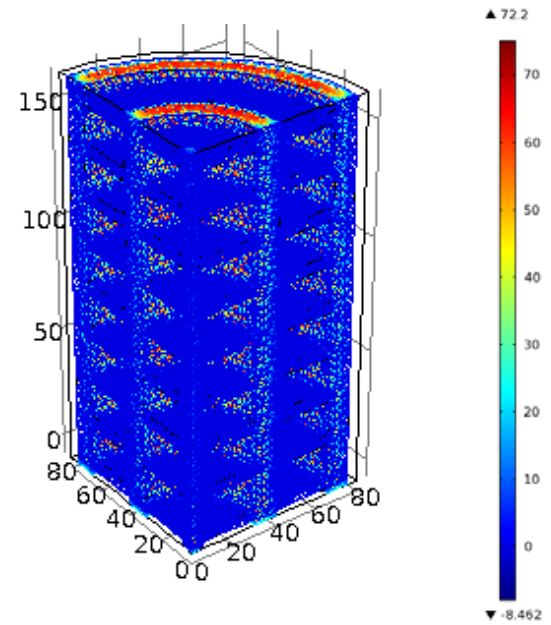

Figure 4b. Mineral oil

Figure 4. $z$-velocity $(\mathrm{mm} / \mathrm{s})$ of both fluids.

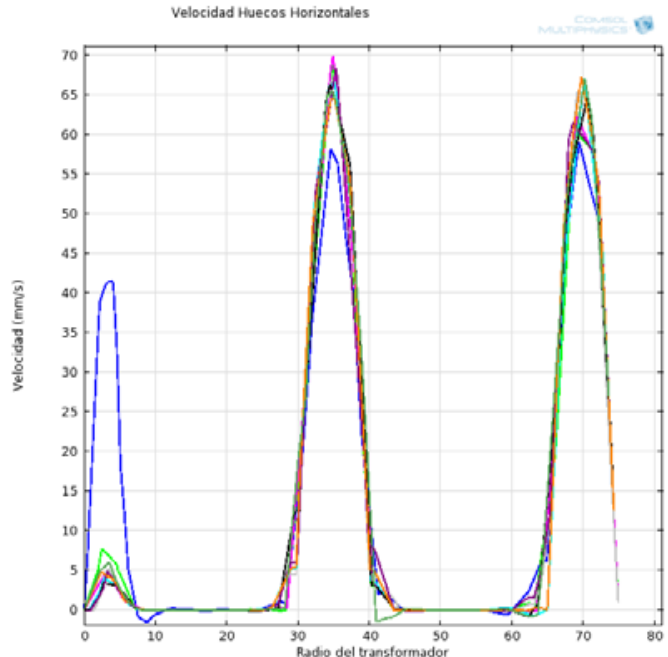

Figure 5a. Vegetable oil

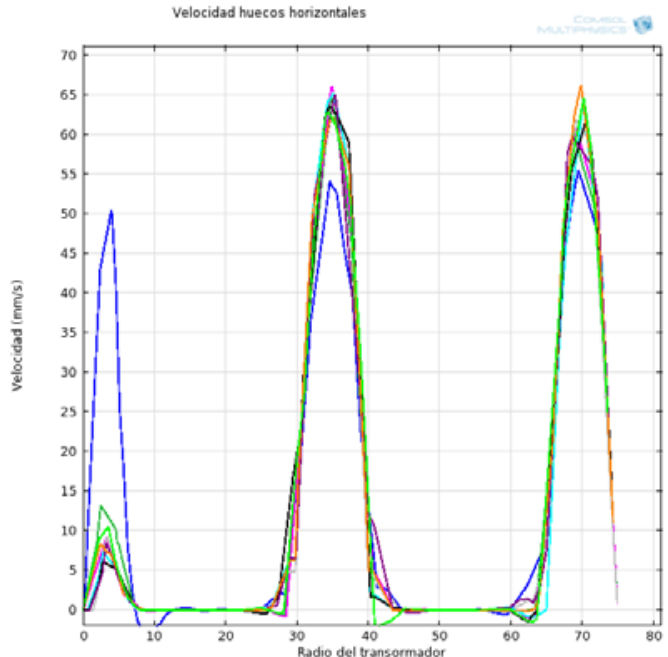

Figure 5b. Mineral oil

Figure 5. $r$-velocity $(\mathrm{mm} / \mathrm{s})$ of both fluids in horizontal channels

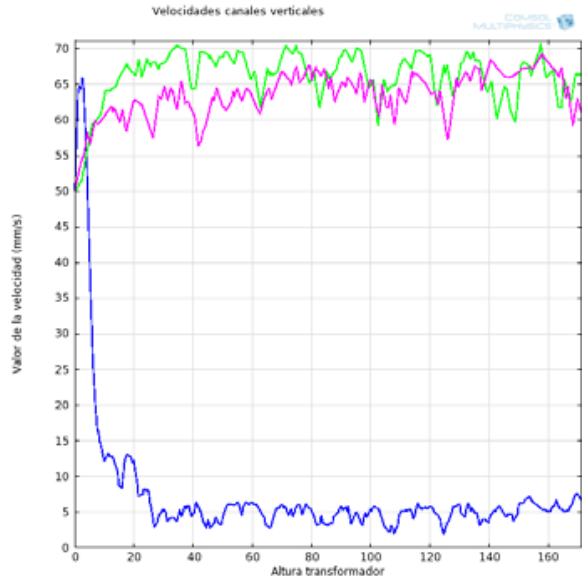

Figure 6a. Vegetable oil

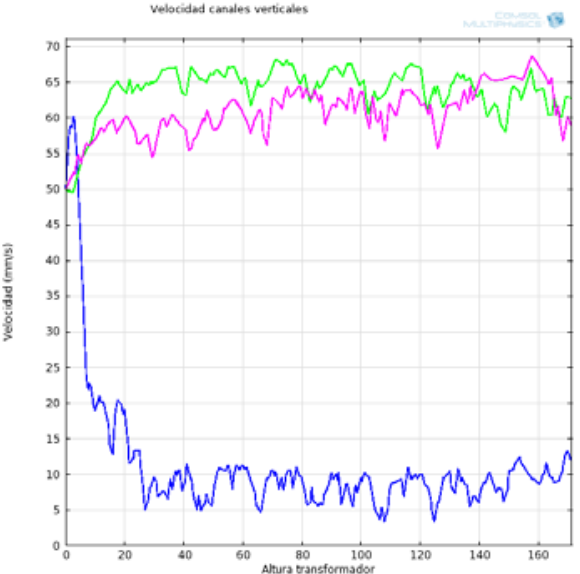

Figure 6b. Mineral oil

Figure 6. $z$-velocity $(\mathrm{mm} / \mathrm{s})$ in vertical channels of both fluids

\section{E. Calculation of the Re number}

The Re number allows to determine how well refrigerates a liquid by means of the calculation of the relation between density, viscosity, velocity and characteristic length of the aforementioned fluid that flows in a geometry: the higher the Re number, the higher is the refrigeration, and vice versa. 
The maximum values of this number, which are obtained in the simulation, have been 3.91 and 15.47 for the natural ester and the mineral oil respectively. That is, it seems that the mineral oil refrigerates better than the vegetable oil.

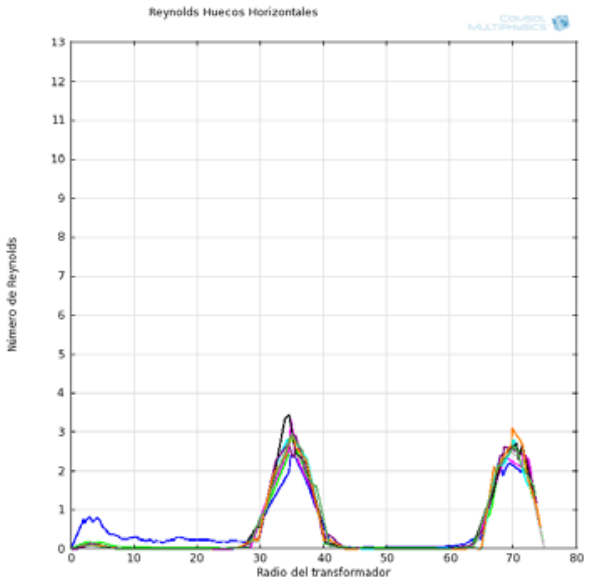

Figure 7a.Vegetable oil
The r-evolution of the Re number in both horizontal and vertical channels at several heights is shown in Figure 7. First, the fluid regime is clearly laminar in all the ducts. However, this number is higher in the two outer vertical channels than in the inner duct while in the horizontal channels is practically zero (except the horizontal lower duct).

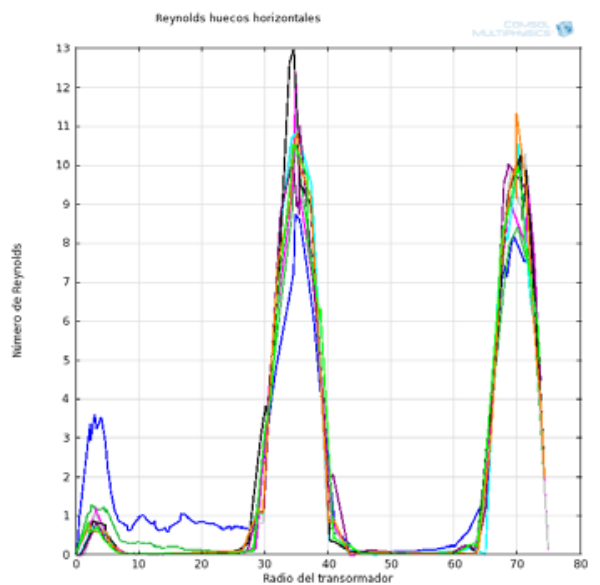

Figura 7b. Mineral oil

Figure 7. r-evolution of Re number of both liquids in horizontal and vertical channels at several heights.

\section{F. Cálculo del número de Prandtl}

The relative thickness of the velocity and the thermal boundary layers is described by the dimensionless Prandtl number. Heat diffuses very slowly in oils ( $\operatorname{Pr}>>1)$ relative to momentum. Consequently the thermal boundary layer is much thinner for oils relative to the velocity boundary layer: the higher is the Pr number,

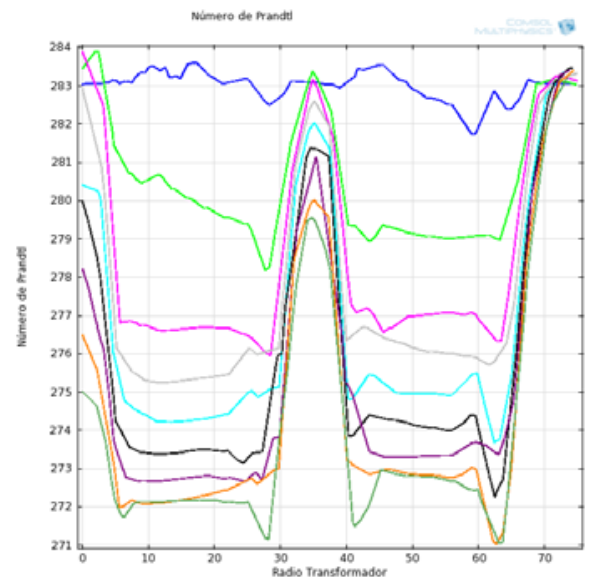

Figure 8a. Vegetable oil the worse is the heat transfer relative to the momentum.

In our case, the maximum values are 96.23 and 288.18 for mineral oil and natural ester respectively (See Figure 8). That is, the heat transfer is worse in the case of natural ester since the velocities of both liquids are similar.

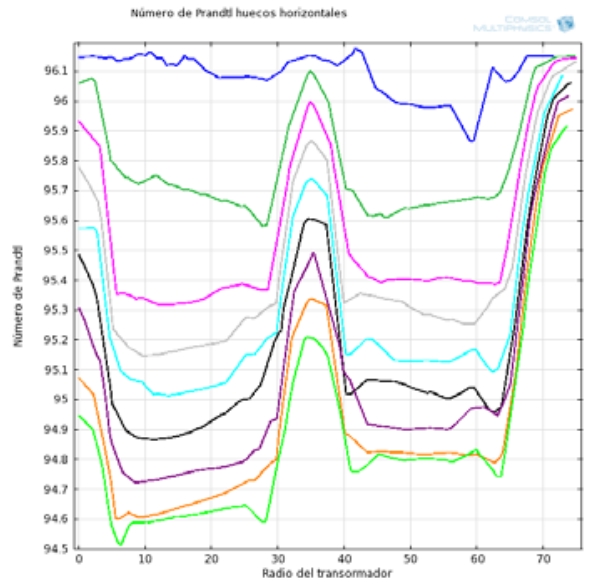

Figura 8b. Mineral oil

Figure 8.

\section{Conclusion}

Some conclusions can be obtained as a result of the analysis of the previous results. For example, in the case of the mineral oil, a faster aging will be caused in the inner coil in comparison to the outer one due to its higher temperature. In contrast, in the case of the natural ester oil, the same aging rhythm of the insulating paper will be produced in both coils due to the isothermal distribution. Nonetheless, the transformer lifetime that is cooled with the vegetable oil can be shortened due to the higher temperatures of the upper part of the windings in comparison with the case of mineral oil.

On the other hand, the linear extrapolation of the temperature results of the inner winding to the total 
column height would lead a significant temperature difference between the vegetable oil and the mineral oil at the top of the transformer. That is, there is a higher probability of occurrence of hot-spots in the aforementioned coil in the case of vegetable oil.

These temperature distributions are due to the movement patterns of the fluids in the horizontal channels. So, in the case of vegetable oil, there is hardly any flow between vertical channels. This allows a uniform heat distribution, which produces an isothermal distribution in the windings. Instead, in the case of mineral oil, an overall convective flow occurs from the intermediate and outer vertical channels towards the inner one through the horizontal channels. This movement pattern is possible due to the higher Reynolds number of the mineral oil in comparison with the natural ester oil. This difference is due to the lower viscosity of the conventional oil, comparing with the new oil. However, this horizontal flow of the mineral oil has a negative effect: an increase of heat accumulated in the top inner part of the transformer occurs, increasing this way the temperature of this area.

Finally, further experimental and theoretical studies of this problem are needed in order to determine the viability of the proposed substitution.

\section{References}

[1] Fernando Delgado, Alfredo Ortiz et al, "Mineral Oil Replacement by Alternative Liquids in Power Transformers”. Paper accepted for publication in the international journal Ingeniería Química, vol.1-2013.

[2] IEEE Guide for Loading Mineral-Oil-Immersed Transformers and Step-Voltage Regulators, IEEE Standard C57.91-2011.

[3] J.M. Mufuta and E. van Den Bulck, "Modeling of mixed convection in the windings of a disc-type power transformer," Applied Thermal Engineering, vol. 20, pp. 417-437, 2000.

[4] Fernando Delgado, Alfredo Ortiz et al, Study on the cooling capacity of alternative liquids in power transformers, ESARS 2012 - International Conference on Electrical Systems for Aircraft, Railway and Ship Propulsion, October 16, 2012.

[5] Nynas Transformer oil Nitro 10GBN, Product Data Sheet, date 2004-02-20. Nynas Naphthenics AB 